\title{
Science and Knowledge Investigation and Decision at 2, 3, 4, 5, n Dimensions
}

\author{
Almada $\mathrm{F}^{1}{ }^{*}$, Fernando $\mathrm{C}^{2}$ and Vicente $\mathrm{A}^{3}$ \\ ${ }^{1}$ Retired University Professor/Independent Researcher, Portugal \\ ${ }^{2}$ University of Madeira, Portugal \\ ${ }^{3}$ University of Beira Interior, Portugal \\ *Corresponding author: Almada F, Retired University Professor/Independent Researcher, Portugal
}

\begin{tabular}{|c|c|}
\hline ARTICLE INFO & ABSTRACT \\
\hline $\begin{array}{l}\text { Received: 蔧 April 16, } 2021 \\
\text { Published: } \text { April 21, } 2021\end{array}$ & $\begin{array}{l}\text { Citation: Almada F, Fernando C, Vicente A. Science and Knowledge Investigation } \\
\text { and Decision at 2, 3, 4, 5, n Dimensions. Biomed J Sci \& Tech Res 35(2)-2021. BJSTR. } \\
\text { MS.ID.005672. }\end{array}$ \\
\hline
\end{tabular}

\section{THE FOUNDATIONS (THE BEDROCK) OF THIS ARTICLE}

\section{Change Happened}

For dozens of years there has been talk about change that would happen, in what would change around us or beyond. Looking out, this is what the look is for, to harvest the rays of light that come to us, to accept them as stimuli, which are transformed into sensations, metamorphose in perceptions that allow us to interpret the world in which we are part and that we are an integral part of (which we often forget). The balances and coherences, of all order, that manage this world in which we are part, can, as such, be shaken, giving way naturally to others, because the world changes by finding new solutions and ways of being to which we must meet and seek to understand why we are dragged in this voraciousness, to which we must be very attentive because, more than observers we are an integral part of the process. Hypotheses must be raised, conjectures batted, solutions must be found and presented and, despite our insignificance when we think in cosmic terms, or even just this planet we inhabit, tiny for the Universe, but huge for man. For it may happen that, almost still, when everything around us changes quickly and violently, we can be surprised by something that we do not predict, we did not even imagine, although it may be even "in front of our eyes".

We are not, however, talking in real motion (a strange word that refers to something that does not exist, but is always dependent on a reference) but in change (whose reference is what existed

previously, which no longer admits the same degrees of freedom in choosing the reference as happens to define movement).

In front of our eyes, on the outside consequently, requiring us only some extrapolation (literally, as a mathematical method) to be able to estimate what would naturally be beyond the range of the original observation (of the outside), what should happen (inside man). And, of course, these concepts of the interior and exterior have only reason to be because the reference we use to observe, that is, the observer, is the (basic) man himself. An extrapolation that must go much further than what our eyes say, because we have many stimulus sensors (the senses, which in fact are not five, but many more; there is no consensus on how many there will be). Senses that, like everything that constitutes man, were not determined at the outset (what departure?), but that were being selected and defined with the experiences of life and evolution (let us not enter through the discussion of nature/nurture, genetics, culture, environment that made so much paint and water run without effectively "making mills move"). Because, really, what we have is a continuum made of dialectics (which some turned into "rhetoric", more interested who were in persuading, or even deceiving, others) and interactions (with which we walk around from Plato or Aristotle, or perhaps more to Zeno of Eleia who with his paradoxes called into question essential things that we should not ignore and that should be the core of the controversies, many and vast, but perhaps not as efficient as one would wish). 
Dialectics and interaction that, if at the beginning, at the base, were practically identical concepts, but that had very different evolutions. This should mean that they would not finally be quite equal (at least in the interpretations they have had, which is a fundamental point for the debate we are looking for here, about the observant man who forgets himself, an integral part of a world that he wants to observe from the 'outside'; and without making the extrapolations that are required - reasons from which it results that errors accumulate, which has consequences, particularly in the coherences and balances, dynamic as well, which we seek to survive, although not only to that end, as we will see below). It is a theme that deserves theoretical deepening, but that can also be treated through some concrete examples that allow the reader to make the necessary extrapolations (as in the mathematical method - starting from some data that define a limited interval you estimate an entire process), that is, that from the cases presented we will naturally estimate beyond the range of the original observation (being the example presented the original observation).

The path we are trying to take here has three aspects:

1. To explore - The search for the unknown which can satisfay personal curiosity and / or (two very different options), the pleasure of walking "the way" (of being "moving", intentionality, which does not mean the existence of the performance of the "walking" function, although it is linked to it - but in this case (walking) the evaluation we make will be "we walk $x$ meters", while in that case the evaluation will be we "experienced $\mathrm{Y}, \mathrm{Z}$, W , while walking");

2. To accumulate - But we cannot ignore the need to communicate to others (which means not only the pleasure of integrating into the group and dialogue, but, above all, allowing a continuity of the process of knowledge production among contemporaries, but also articulating the past with the future), whichever is possible (we cannot forget the obstacles proper to communication) of the experiences we enjoy (communicating is not only interacting, but is a dialogue in which the receiver and the emitter, through a medium (image, speech, writing, body attitudes, etc.)., in a dialectical process, they seek to convey messages, which, although they have different meanings for each of them, allow interpretations that are close enough to be able to consider that they understand each other.

3. To transform - With, possibly, a third strand: a concern and an intentionality (therefore aiming at objectives, that is, with a purpose) of obtaining transformative results, acting (the function is the act aiming at change) on the existing balances and coherences to cause them changes (which means the pleasure of performing)

[Note: The number of ' that we were obliged to put is an indicator of the need for special care about the meanings of the terms used. Like what we did above, and will do again bellow, with dialectics and interaction.]
A concern with three distinct strands, which sometimes have divergent or even contradictory implications and trends, which requires a lot of attention and, of course, subterfuges and specific care. Science and knowledge in general to justify the investments (human, material, financial, social, etc.) they need, cannot but worry about these three strands. Only, thus (it was understood and explained; it was transmitted, allowing the accumulation of knowledge encompassing not only the members of the group, but also the passage from generation to generation; there is an intentionality, a sense of action, which goes beyond mere chance), the design of research being a mean for decision is fulfilled. It is thus clear that so important is the transformation we make from the unknown to knowledge, as the identification of what we do not know, and, consequently, of the limits of knowledge. Uncertainty and ignorance are, therefore, aspects that we must deal with simplicity, with naturalness and authenticity, overcoming routines and vices that are in the past (which lasted until recently, dozens of years, which in evolutionary terms is an instant) in which the ruptures and continuities have happened, according to the existing constraints and possible capabilities.

But science and knowledge have changed again in nature.

The object, and hence the nature of science, is no longer (it has never been, but there were those who were convinced of it):

a) In the investigation of the truth

b) Or in the search for data (from positivists, for example) that in its apparent neutrality (the Inquisition and similar things left deep marks) did not compromise the researcher.

c) Or in the "magic key" to obtaining prestigious places (although often underpaid, if we consider the average of the salaries earned and the paths that were necessary to reach them).

d) Or in an exotic activity for some marginals to society who found their pretexts for living.

e) Or in a set of liturgies to be held on the altar of the laboratory in honor of somewhat esoteric deities (secrecy is also sometimes used as the safeguarding of emptiness).

Or, still, in the thousands of other things that science was or seemed to be, in the pretexts for intentions and designs that will not be worth discussing here.

But science, to fulfill the functions that we show above, very succinctly with three aspects (being is fulfilling the function, not only assuming the designation of), has to integrate (our assessment is made more simple if we observe the phenomenon in the context in which it integrates, because it shows the functionality it has by the interactions it manages to establish, although the analysis makes it possible to identify the details that would otherwise be difficult to detect), namely: 
a. In a context encompassing knowledge in general (which facilitates adjustment to the needs of transmission - see, above, strand 2; and the transformative function - see, above, strand 3 ), that it is an optimized way to monetize (less costs and/or more benefits) resources.

b. In existing research - which facilitates the obtaining of the means, the available tools (materials and conceptual), [Note: See the importance of instruments in the evolutionary process of science - Ian Hacking].

c. In the concerns of the different frames of science (of the sciences?), but also of individuals and societies.

d. In the aspirations and desires that define the objectives to be fulfilled.

e. In a global framework involving, namely, science, knowledge in general, research, decision (in its specific scope and because by the object and nature of its own it is a powerful tool for those who know how to use it).

With a concern to be another of the agents of dialectics that define and mark the way forward, without an elitist tendency (which sometimes intend to impose on it, perhaps even because they do not know what science is - see above the object and nature of science), but without forgetting that it is dedicated to a path, as above we defend, "searching for and/or in (two very different options) unknown", which gives you specific privileges and responsibilities, for which you will have to follow and contribute to build change in the generic framework (a sketch) that above we leave to "surround" the proposals and suggestions that we make bellow, by presenting some points, so that the reader from them can extrapolate (literally, as a mathematical method) an overall view of science, its framework and the evolutionary process we suggest.

In this way, we seek to build (by articulating this article with several others that we have been publishing) a support platform for a debate that contributes to the rupture that so many advocates today, but which is late to happen.

\section{Change Happened-Yes}

But the break that would give him coherence and balance did not. That is why we are experiencing successive crises without being able to overcome the sense of lack of support that will allow us to overcome the obstacles that are in our way. Without solid foundations it is natural for this to happen. Now we start from a knowledge that for centuries had a sufficiently restricted nucleus, which was treated by a circumscribed number of researchers, which allowed a certain uniformity. Even so, when we go a little deeper into the subject, we see that the East, the Middle East, North Africa, Europe, to not go any further, differed in the conceptions they had, in the searches they were making, in the processes they used. But the distances and time to travel between them were such that, seen from as far as we do now, the shocks and conflicts (which involved and provoked, destruction, wars, exterminations, acculturation, subjections), constituted pieces of a huge puzzle that to lack of better was overcome. The ruptures (perhaps not the necessary) were made, we survived (some at least).

But it all blew up. And the scale of the problem too. The number of researchers, the amount of knowledge available, the means to treat and communicate it grows exponentially, the "schools of thought", the interests (of various natures) involved, technological and material resources in general, are more and more, bigger and more powerful. Survival is imposed (and that are not only a few to survive, and that may be the ones necessary). For what we cannot count on the weaknesses (which in their weakness were forces to resist the shocks and conflicts that we pointed out above). It is in our ability to reflect and equate the problems that we live through that we must find the capacity to resist and survive and, at the same time, to enjoy the enormous treasures (material but let us not forget it, also conceptual) that we have, if we know how to use them, in a fruitful way.

It is in this sense that we leave some suggestions and recommendations. For what we were careful to leave framing and foundations, although very briefly (the article contingencies impose it), raising some controversial issues, but which we consider essential at the beginning of this article, although we run the risk of the reader being able to consider them a little displaced, because he was obliged to estimate what would naturally be beyond the range of the original observation, to make extrapolations that would help to fill the empty spaces. We are trying to overcome this difficulty, alerting to the existence of other works and with the intention of through a sum of positions we are trying, little by little, to carry out a work that establishes and consolidates support for continuity, either with articles already published, or in the form of new articles, or also with books and other types of communication, for which we have already left bridges and connections. The realization of the rupture, to which we seek to contribute, imposes the search for solutions that allow to facilitate change and consolidate what Kuhn called "the new normal". Then we add some points so that the reader has a reference to extrapolate. But, as with any theme, we always must extrapolate from some parts that we can observe to a whole that is beyond the 'observed interval' and that we try to achieve through estimates.

\section{Structuring Points for the Reader to Extrapolate}

Point 1: Science does not exist. What exists are sciences, with functions, structures, methodologies, habits, addictions and even different liturgies. (Figure 1) The term science (not to be confused with the idea THE SCIENCE) is a broad concept (such as - medicine, sport, education), which encompasses many different and sometimes even divergent things, in the concerns they have, in the objectives they seek, in the paths they follow, As we defend in the 
article "Sport as a Mean of Solicitation, Transformation, Evolution and Education of Man" [1] in which starting from an image of an arc we show, allegorically, the articulation of the multiple areas of knowledge (Figure 2).

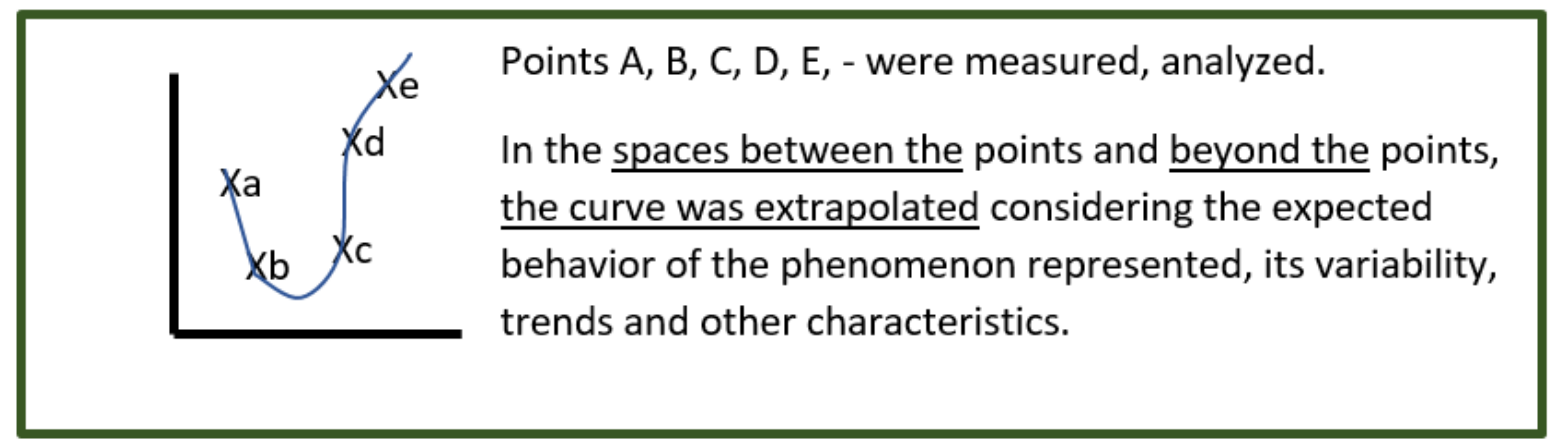

Figure 1.

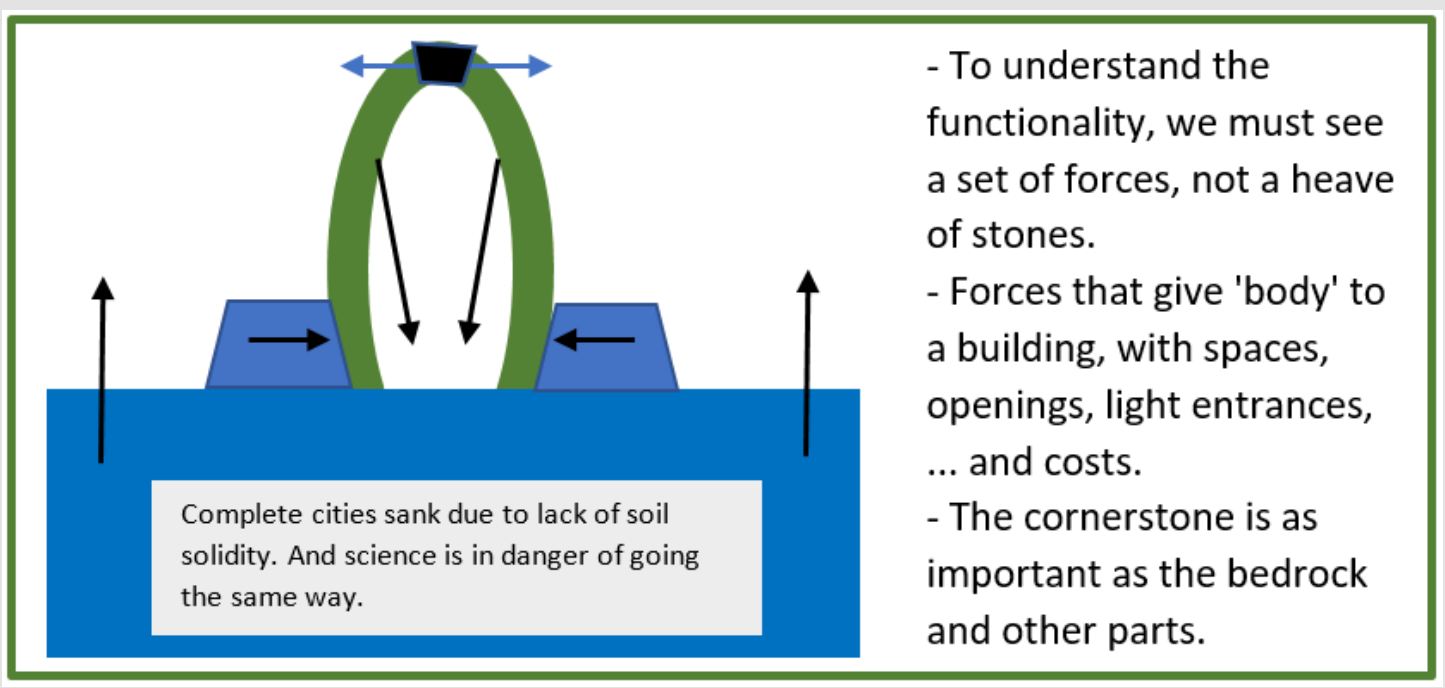

Figure 2.

Point 2 - Specialization Can Be A Trap - at a time, as today, when the WORK increasingly requires the collaboration of different knowledge, skills, capabilities. Points A, B, C, D, E, - were measured, analyzed according to the same criteria and parameters. Otherwise, the curve has no coherence and loses meaning. The curve thus has an integrative sense that combines the different events (A, B, C, D, E) in an aggregating process. We see the world always from segmentary aspects, building from them a vision of the global, which we never observe in its entirety - which has its consequences.

In the article "A Brief Contribution to Understand the Structure of Knowledge and The Construction of Science" [2] we seek to show how:

a. The evaluation of education - must be done in industry, in quality of life, in economy, in social dynamics.

b. The evaluation of the economy - which must be done in the political framework, in health, in education. c. The evaluation of the policy - which must be done in the economy, in education, in health, in transportation.

d. The evaluation of industry - which must be done, in the economy, in the market, in education.

e. The assessment of the market - which must be done, in economics, in education, in science.

Or else the evaluations are merely rituals and myths, out of context of global coherence (even if coherent at the local level) and the balances that give fluidity and efficiency to the processes. Enclosed in the restricted spaces of each of these fields we lose the notion of the global and it is easy to fall into vicious circles from where it is often difficult to leave because we lose the notion of the mistakes that are made exist.

Point 3: The Structure of science, of knowledge in general, if it is seen in a fragmented way, the notion of whole and of the balances (macro) and of the coherences (macro + macro) to it (the science) 
cannot fail to obey is lost. From a central core, specializations and autonomy of fields and areas of knowledge diverge and move further and further away. At the same time, the debate areas and objects of study is increasingly pressing towards that the pleasure of performing (see "strand 3" above) may take place, so that the cumulative factor (see "strand 2" above) can be exploited efficiently, and for that the pleasure of walking 'the way' (see "strand 1" above) can happen. However, good intentions are not enough. In Point 1 and 2, we suggest measures so that the operationalization that we advocate here can happen. In Point 4 we present an overview of increasingly available potentialities that can be a wealth or an embarrassment, depending on the ability we must deal with them.

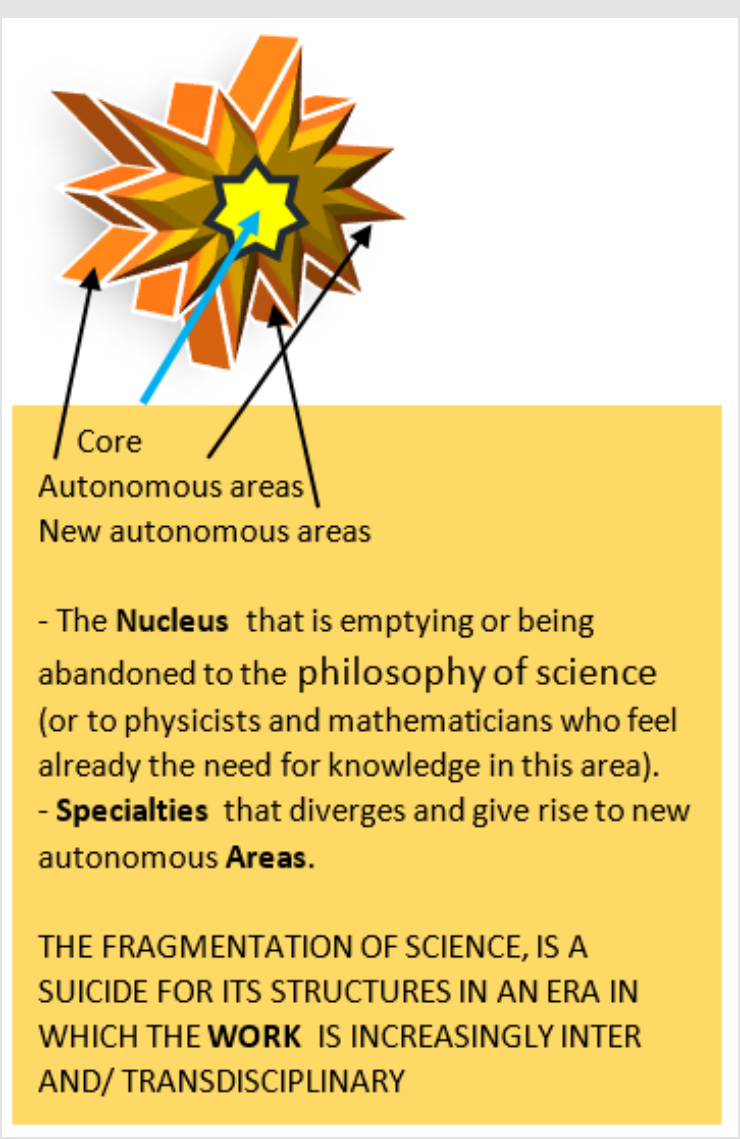

Figure 3.

It is not enough to interact, dialectics must gain intentionality and be inserted in an overall vision that allows a coherent, balanced and integrated development policy (or policies). Diverge to divide autonomies and focus of power is suicide for the structures and professionals of science (from researcher to disseminator, from laboratory technician to teacher, from equipment manufacturer to service and media trader) at a time when more and more teams need to integrate more specialties and skills. For example, universities must adapt, moving from distributors and knowledge disseminators, with specialists in each of the areas (who today already have difficulty in fulfilling theirs functions and are not competitive against online information), to capacity generators to work in an integrated and articulated way, in teams and with specialists able to integrate taskforces according to needs.

The suggestions for solutions (as we refer at the end of this article with which we will soon publish with the title "The Next Decisive Technological Leap") must emerge for the discussion and the challenge to take place, the confrontation takes place (let us not forget what is at stake (surviving is imposed - we said above, without seeking to be dramatic). As we say in Point 4 the means and resources available, exist, but are far from being exploited in a useful and efficient way, because "yesterday's man" is not able to do so and "the man of today" has not yet emerged (and even less the one of tomorrow; a tomorrow where we will be when we have made the preparations to act; with a later than tomorrow where we can still enjoy it, there are three strands as we saw, from what we have done).

Point 4 - The Resources and Tools Available Are Not Purposes in Itself, they are Means to Act. More resources and tools can be useful if they contribute to the objectives pursued in an efficient way, therefore at the service of a strategy. Without this they can be a nuisance (or a simple exercise of ostentation). The abundance of sensors and instruments is increasing. With the ability to measure that we already have today and that will explosively increase. Any situation can be a sensor (see Point 6) if we have models integrating the different variables involved and the values of the indicators that we should expect for each case.

For example, the thermometer is a sensor, widely used, because we know how to interpret the values, we have gotten to try to detect an anomaly. Fever, for example, is often a mere indicator that something is wrong. Eliminating fever may not be favorable if we do not correct the causes that are at its origin. Understanding functionality allows us to recognize what intervention we should have to reset the desirable balances (i.e., what is wrong, where to correct and, of course, what may be desirable). But understanding the functionality, how the phenomenon evaluated works, goes far beyond the description, the operation of the parts, the inventory of the components and even some aspects. Implies understanding the dynamics of the process and therefore the interactions and dialectics (interns and sometimes with the outside).

\section{Point 5: Methodologies are Structuring}

They must fulfill the function and serve the pursuit of the objectives aimed as efficiently as possible and not be considered as an enchanting talisman. One of the fields in which more restructuring and readjustments must be done is, with no doubt, the methodologies used, and the use of the processes used. In the impossibility of in the context of an article enter minimally in this theme, but considering it essential (although rarely treated), we will briefly address the transformations imposed by the number 
of dimensions considered. A theme that is closely linked to the theme dealt with in the previous point. Again, we will use an image easily interpretable by the reader to simplify the presentation. We will show (figure 4.) the representation of a point (the simplest object), to exemplify how difficulties grow with the increase of the dimensions considered. The dimensions considered when we appreciate the context of which we are part, depend on our ability, because everything what exists always have $\mathrm{n}$ dimensions.

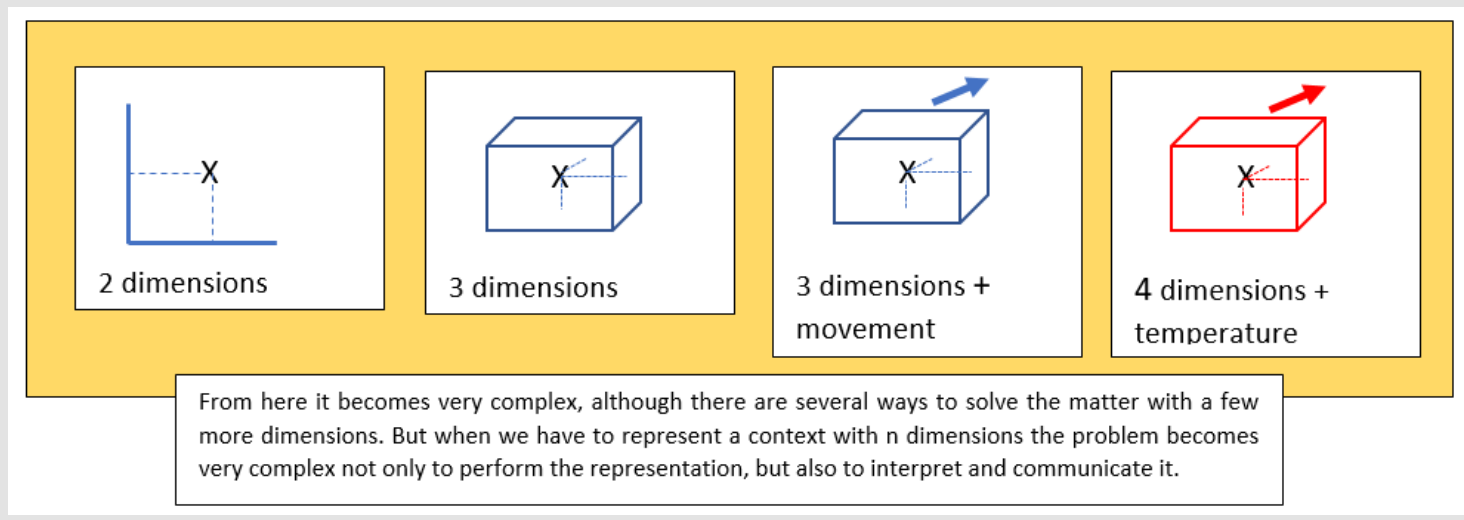

Figure 4 .

We also draw attention to the following topics in the framework of methodologies:

a) It is true that some perspectives represented in two dimensions give the notion of depth ( 3 dimensions), but it is an "optical illusion", a perception" - not useful in methodologies.

b) One of the problems we have when we think about the context in which we integrate, of which we are part, and we want to communicate thought, without restricting many the dimensions considered, is in the ways of representing, describing, this thought.

c) One difficulty that we face, we readers and thinkers of the context through science, is to be (using the triple relationship that Einstein proposed to us, phenomenon / sign / observer) simultaneously part of the phenomenon, observers and even part of the different signs, through the senses, with which we detect the phenomenon.

d) The enormous amount of information we use, and face certainly has implications for science and knowledge in general. Some of the solutions of the past do not fit the new needs. We give two examples below:

a. The representation, recording and transmission of these amounts of information may not be made predominantly by writing on paper or orally.

b. The "avatars" and the like will certainly respond to the previous point once the essential adaptations, in the media used and in the users.

e) Users of science and knowledge in general should have the skills to deal with the new and many resources available without losing objectivity. Two examples: a. The $p$ value of statistical probabilities is a tool that aims to indicate "statistical significance". Some, many, have transformed it into a "sesame open" to the realms of science with a profusion of data, without even adapting to the context and processes in which it is used.

b. In these points on methodology, we use an image to show implications of the variation of the amount of information, the influence on transmitters and receivers of information and knowledge. We are convinced that many readers valued the image more, a caricature in our message, without bridging the gap to the essentials, methodologies, as tools that they are. Methodologies cannot escape these, and many others, aspects and, of course, will have to adjust and compromises to solve them.

Point 6 - A sensor is what allows us to detect the existence (or not) of an anomaly. So, we must have a notion of the "normal". The sports can also be considered as a sensor if they are seen by the features, it plays which implies a profound transformation (in the structural sense) in knowledge, a "great" rupture (great is only a way of pointing out, because the ruptures occur or do not occur, they are always huge). A break no longer:

A. Considering each sport as "a sports activity that is composed of a set of techniques, which practitioners (those who do their practice - actuators, not agents of) must know, to be able to imitate the champions".

B. To see it as a model that integrates a coherent set of requests (articulation of immediate objectives with the mediate objectives - which is one of the great treasures of sport and allows the implicit motivation of the sportsman to seek his limits), that are known the variables involved and the respective indicators, as 
well as the values that they should have (expectations) in different situations. Thus, the function of the coach is not to bring the sportsman closer to the standard considered optimal, but through a diagnosis seek to define the variables that can be changed to gain efficiency, prescribing the appropriate (active principles) exercises and controlling the sportsman evolution.

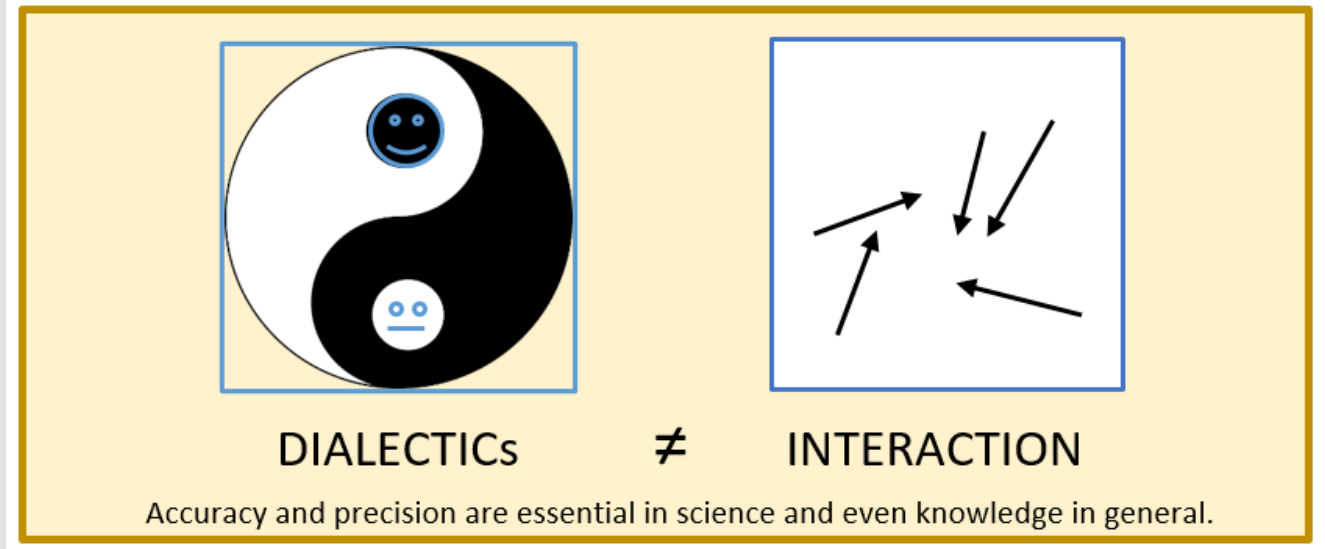

Figure 5.

In fact, "a great rupture", already made in conceptual terms, but which needs the structures and professionals capable of operationalizing it - see Points 1, 2, 3, 4 and 5, among other ruptures that have to be carried out not only in the specific field of sport, but in the very conception of the structure of the individual (which is a whole although it can be seen under different facets) and in the dynamics of society (of societies?). For example, golf and judo request different variables, with different requested behaviors, with indicators specific to the different situations experienced, integrated into models of different sports activities, requiring different diagnoses, prescriptions, and controls and, of course, with different effects. They are not different just because the techniques are different, and one is done on the golf course and the other on the judo tatami. The problem is inverse, the golf course and tatami are different because they respond to different needs (that must be identified to understand the different processes of ich one).

Making the connection to concepts treated at the beginning of this work we will say that judo implies a dialectic, being a sequence of stops/responses, while golf will be another interaction in which the player articulates not only with the other players who are in competition (as in judo), but also with scores that were made at other times and in other competitions. Talking about the advantage of doing sport (generic) is the same as saying of the need to eat food, to take medicines, to gain education, does not have any meaning (being able to give a good conversation such as talking about time, when we cannot, or do not know, to say anything else). Standing by the branches, unable to identify the specificities, the differences (which requires interdisciplinarity or even transdisciplinarity) we are left by generalities that translate incapacity and incompetence in the world in which we live today and with the knowledge that is available today.

\section{Conclusion}

Science, knowledge in general, are powerful tools. But a tool needs a work. A work requires a "master" to build and a user to use. A set that must be balanced and coherent not only to be efficient, but also to have a reason to be. Man, in his insignificance, because it is from his point of view that we "look" (an expression that does not mean that we have forgotten all others, many, senses), is the problem, the answer, the agent, the author, the object and the target. But, we think, the rupture must happen by passing (starting?) by the notion that we have of man. Because the notion of chance and natural selection for millions of years, that today is defended as the privileged form that led to the evolution of man so that this is what it is currently, will not be enough to understand the process followed. As well as the ways we must intervene (in the fields of education, training, health) competently in gaining skills, performances and in the different dynamic balances and coherences on which depend the potential that we have in all the action of man to live and find more efficient ways to continue his journey.

It is essential to go to the functionalities of man, not to the functionalities of the different "pieces that make up man", but to the underlying features that underlie the whole, where this whole is supported, roots that are not more important than the other elements of the plant, but that grab it (attach) to the ground (see foundations and types of sciences Point 1). In this sense and continuing in the logic on which we have based our work we will present in the form of a book, it takes space to present defend and justify, fulfilling the three strands and according to the methodologies and processes that we present above, which we will soon publish with the title "THE NEXT DECISIVE TECHNOLOGICAL LEAP". 


\section{References}

1. Almada F, Fernando C, Lopes H, Vicente A (2020) Sport as a Mean of Solicitation, Transformation, Evolution and Education of Man. Journal of Physical Fitness, Medicine \& Treatment in Sports 7(2).

\section{ISSN: 2574-1241}

DOI: 10.26717/BJSTR.2021.35.005672

Almada F. Biomed J Sci \& Tech Res

(c) (P) This work is licensed under Creative

Submission Link: https://biomedres.us/submit-manuscript.php
2. Almada F, Fernando C, Vicente A (2021) A Brief Contribution to Understand the Structure of Knowledge and The Construction of Science. Journal of Physical Fitness, Medicine \& Treatment in Sports 8(4).

\begin{tabular}{ll} 
BIOMEDICAL & Assets of Publishing with us \\
RESEARCHES & - Global archiving of articles \\
\hline Immediate, unrestricted online access & - Rigorous Peer Review Process \\
& - Anthors Retain Copyrights
\end{tabular}

